\title{
Quality Assessment of Radio News in Afghanistan (BBC, Killid, Azadi, \& Afghanistan)
}

\author{
Farid Ahamd Monib ${ }^{1,2}$, Jamaluddin Qanet ${ }^{2}$ \\ ${ }^{1}$ Department of Media and Communication Studies, Al-Beroni University, Kohistan, Afghanistan \\ ${ }^{2}$ Dunya University, Kabul, Afghanistan \\ Email:afaridmonib@gmail.com,prof.faridmonib@au.edu.af, jamalqanet@gmail.com
}

How to cite this paper: Monib, F. A., \& Qanet, J. (2020). Quality Assessment of Radio News in Afghanistan (BBC, Killid, Azadi, \& Afghanistan). Advances in Journalism and Communication, 8, 97-116. https://doi.org/10.4236/ajc.2020.84008

Received: October 4, 2020

Accepted: December 1, 2020

Published: December 4, 2020

Copyright (c) 2020 by author(s) and Scientific Research Publishing Inc. This work is licensed under the Creative Commons Attribution International License (CC BY 4.0).

http://creativecommons.org/licenses/by/4.0/

(c) (i) Open Access

\begin{abstract}
This study identifies and evaluates the quality assessment of radio news in the country. To conduct this research, the researcher first posed the questions and objectives of the research and then, according to the nature of the work, used exploratory and applied research. The researcher consulted with professors from Al-Beroni and Kabul University to choose the research method and used quantitative method to collect information and qualitative content analysis method to analyze and interpret information. The researcher selected 4 half-hour news programs of Afghanistan, Killid, Azadi and BBC radios from the 6 months of news programs of the mentioned media as a sample population and after analyzing them with remarkable and interesting results acquired. BBC Radio follows all principles and standards of journalism and news reporting in radio, but the writing style of BBC Radio vocabulary is not simple and limited, so it is sometimes difficult for listeners to understand the news events or news programs. On the contrary, Radio Azadi's writing style and reporting as well as presentation of news program is very simple, and listeners immediately can get the concept of news items. Independent and private radio stations follow development system as well as social responsibility theory of the media, but foreign media have their specific system of covering the events.
\end{abstract}

\section{Keywords}

Radio Station, Quality, Radio News, Radio Report, Qualitative Content Analysis, Kabul, Afghanistan

\section{Introduction}

Radio is a fascination medium among the various mass communication media, because of its special characteristics (Chantler \& Stewart, 2013). It continues to 
be as relevant and potent as it was in the early years despite the emergence of more glamorous media (Chantler \& Stewart, 2009). It is a truism that in the first phase of broadcasting spanning decades from the early twenties, radio reigned alone or was the dominant player. If we compare it to other mass media, radio consistently ranks as the most popular means of disseminating information, regardless of the continent (Filak, 2018).

The aim of this research/research is to investigate and analyze the quality of radio news programs in Afghanistan, by using the broadcasting news magazine from Afghanistan radio channels as content analysis. The arts of news broadcasting in four radio stations; Radio Afghanistan which is governmental medium, Killid Radio; which is private as well as local radio station, BBC Radio channel; which is used in United Kingdom (UK) as well as international radio station and Radio Free Afghanistan (RFA); which is supported by USA and broadcasts from Prague, Czech Republic, analyze suing the news with sound bites, and reports in a news magazine programs of the four radio stations. This research hypothesis requires a content analysis of the four news magazines of above channels.

According to Nai. (Supporting open media in Afghanistan) 2008-now; around 85 - 95 percent population of Afghanistan are listening to radio, especially radio news programs (Altai-Consulting \& Internews, 2014; ACSOR-Surveys, 2010; Gordon, 2005). This research hypothesis is radio which is the most effective medium in Afghanistan as well as radio news programs which have much more effects on society; so, this research is based on quality of radio news magazine in the country.

The study firstly investigates how much news was broadcast in the 10 news magazines or each radio stations over a specific time frame, and will show how much of news is about politics, national security and terrorism activities, economic, culture, narcotic news, international news only and some international news which is relevant to Afghanistan.

We analyze use of the openers and headlines, form of the news reports, length of news reports, geographic reference, regional reference, international references, number of sound bites and number of sound bites providers, in one section. But in another section of this research we analyze the re-grouped topics, re-grouped actors, reporting style, number of depth levels, perspectives sources and sound bites.

Secondly, the study compares the coverage of all news items with its characteristics and elements in four radio stations. In review of literature we studied basic information about mass communication and mass media as well as radio itself, radio programs with its ethics and standards, and radio writing and program formats and definition of journalism and its profession from the references which are cited in (Gordon, 2005; ACSOR-Surveys, 2010; Altai Consulting \& Internews, 2014 \& 2017; BBC Media Action, 2012; Broadcasting Board of Governors (BBG) \& GALLUP, 2015; Fraenkel, Schoemaker, \& Himelfarb, 2014; Engstrom, 
2020; Jawad, 2013; Chapman \& Kinsey, 2009, Bajraktari \& Parajon, 2008).

By study of this research, the question of what kind of news reports and time duration of all news magazines, the radio stations are broadcasting out to the public and society, can be answered. On the surface, it seems that news magazines thriving in Afghanistan radio stations. Each major radio channels in my sample has daily news magazine.

Given that the purpose of the work is to build on propositions from existing research, it is necessary to work within the framework established by that research; that means adopting a narrow focus that looks at one segment of the Afghanistan radio news quality and radio newscasts. This seems reasonable given that radio has been recognized as an important tool for political communication, access to information in all areas, battle against narcotic arable, entertainment, and education as well as people connection with the country and that news is recognized as a particularly important genre for that kind of communication.

Content analysis a summarizing any form of content by counting various aspects of the content. Content analysis, though it often analysis written words, is a quantitative research method. The results of content analysis are number and percentage after doing a content analysis, you might make a statement such as $35 \%$ news magazine an average of approximately one the $(32.9 \%)$ of all the news pieces are opened in the headlines of Afghanistan's radio stations. also, content analysis is always through.

At first time, method has done after world war two; this research showed that how much public song is broadcasting from radio stations in Europe and America. Then researchers paid attention to content analysis of propaganda in newspapers and radio studies. In 1952 Bernard Berline published a book by the name of content analysis in communication studies. Also Koper and Dopane's research in 1994 showed that $26 \%$ of all mass media research from (1965-1989) has done by using of content analysis (Prasad, 2019). Day by day the research and using of this method has grown. It is better method for data collection.

The previous investigations have not examined in a systematic way a number of key factors - the quality of news magazine or news bulletin, the production process, content of newscasts, attitudes toward public service broadcasting as well as private and independent broadcasting, and attitudes toward the role of the international community-means there is a possibility that the propositions may not have as solid a grounding as they might (Engstrom, 2020).

\section{Method and Materials}

This study is exploratory research to develop radio news. This research analyzed the quality assessment of radio news bulletin as well as radio news magazine in Afghanistan. The method of this research is qualitative as a content analysis. This researcher used simple random sampling method, which each element in the population has an equal chance of being selected is referred to as simple random sampling. 
For example, in this research the researcher selected from four radio stations; 10 news magazines of each radio channels including: Radio Afghanistan, Killid Radio, BBC Radio and Azadi Radio. The researcher chose 10 equal news magazines of each medium from five months' texts as well as audio recorded news programs of them, which are available with me. This research as the researcher mentioned above, was systematic random sampling. The sample consists of the main news broadcasts of the same period of time, from (Augest 25/2019 to January 15/2020), five months, from four different Afghanistan Radio broadcasters.

Altogether the sample consists of 615 news items. Table 1 shows the number of news pieces by daily news magazines of each above radio channels: Radio Afghanistan broadcast 162 news pieces in 10 news magazines; Killid Radio broadcast 159 news pieces; BBC Radio broadcast 141 news pieces; and Azadi Radio broadcast 153 news pieces each of them in 10 news magazines from each.

These contents organized and supported by researcher to carry out recording, transcription collection of all news programs and texts and coding. The respective data were transmitted by me to India for analysis of these contents. The researcher examined and analyzed the coding sheets, the latter by means of statistical analysis.

After recording the news every news magazine of above dates as I mentioned the news were transcript verbatim. The transcripts were sent to my house, where the different news pieces which belonged together were assembled in to one news story. This has to be seen against the background that Afghanistan's radio news stories have a specific piece's composition: parts of one news story are mentioned in the opener section, the main part, then in the news magazine section, and further elaborations are the news magazine section, which has headlines or openers, news pieces only, dispatch, package and commentary of the specific news magazines.

Table 1. Sample of radio news reports/pieces.

\begin{tabular}{cccccc}
\hline \multirow{2}{*}{ Date } & \multicolumn{5}{c}{ Medium } \\
\cline { 2 - 5 } & BBC Radio & Afghanistan & Killid Radio & Azadi Radio & \\
\hline August 25 & 12 & 15 & 14 & 13 & 54 \\
September 8 & 15 & 17 & 18 & 14 & 64 \\
September 22 & 16 & 19 & 15 & 16 & 66 \\
October 14 & 13 & 14 & 17 & 15 & 59 \\
October 27 & 16 & 16 & 14 & 18 & 64 \\
November 15 & 14 & 13 & 19 & 15 & 61 \\
November 28 & 15 & 21 & 13 & 14 & 63 \\
December 9 & 14 & 15 & 14 & 17 & 60 \\
December 27 & 14 & 16 & 17 & 16 & 63 \\
January 15 & 12 & 16 & 18 & 15 & 61 \\
Total No. & 141 & 162 & 159 & 153 & 615 \\
\hline
\end{tabular}


A team of coders, who wanted help me, carried out the coding of the revised transcripts. They all had participated in two days' information on content analysis of radio news and application of the codebook. The course was run by the researcher. Table 2 shows coders were selected and supervised by me. Every four news magazine of each day from each radio channels type was coded by two people; this procedure should allow research team to compare the obtained data and to draw conclusions concerning their quality and accordingly their reliability. For the same purpose the research team also re-coded a part of the news magazine. The coding sheets were then directly sent to the researcher, were the processing (completing and collating of all data into one file) and statistical analysis SPSS took place. Based on various reliability checks, resulting in a priority list of coder, the final sample was identified. In this sample some coders have a larger share than others as their coding results, seem to be more trust worthy.

\section{Findings and Analysis}

Several formal aspects concerning the composition of the news magazines were assessed. They provide information about the references of different radio broadcasters when it comes e.g. to news size and use of sound-bites on reports, like; dispatch, package and commentary. This section just describes these characteristics, but they do not refer to quality.

Openers are the short headlines that open a news magazine as well as news bulletin announcing a longer news report broadcasts in Afghanistan have a distributive three-piece composition in common: after the headlines on overview over all the news stories is given, usually referred to as the some of those news later on is elaborated more in the news magazine, though not necessary all the headlines or stories of the news magazine are covered there. According to Table 3

Table 2. Number of each coded by each coder.

\begin{tabular}{|c|c|c|c|c|c|}
\hline \multirow{2}{*}{ Coder } & \multicolumn{4}{|c|}{ Medium } & \multirow{2}{*}{ Total No. } \\
\hline & BBC Radio & Afghanistan & Killid Radio & Radio Azadi & \\
\hline Coder 1 & 12 & 15 & 14 & 13 & 54 \\
\hline Coder 2 & 15 & 17 & 18 & 14 & 64 \\
\hline Coder 3 & 16 & 19 & 15 & 16 & 66 \\
\hline Coder 4 & 13 & 14 & 17 & 15 & 59 \\
\hline Coder 5 & 16 & 16 & 14 & 18 & 64 \\
\hline Coder 6 & 14 & 13 & 19 & 15 & 61 \\
\hline Coder 7 & 15 & 21 & 13 & 14 & 63 \\
\hline Coder 8 & 14 & 15 & 14 & 17 & 60 \\
\hline Coder 9 & 14 & 16 & 17 & 16 & 63 \\
\hline Coder 10 & 12 & 16 & 18 & 15 & 61 \\
\hline Total No. & 141 & 162 & 159 & 153 & 615 \\
\hline
\end{tabular}


Table 3. Use of openers/headlines.

\begin{tabular}{cccccc}
\hline \multirow{2}{*}{ Openers/headlines } & \multicolumn{5}{c}{ Medium } \\
\cline { 2 - 5 } & BBC Radio & Afghanistan & Killid Radio & Radio Azadi & \\
\hline Yes & $35.0 \%$ & $26.0 \%$ & $42.1 \%$ & $30.8 \%$ & $32.9 \%$ \\
No & $65.0 \%$ & $74.0 \%$ & $57.9 \%$ & $69.2 \%$ & $67.1 \%$ \\
Total No. & 141 & 162 & 159 & 153 & 615 \\
$\%$ & 100 & 100 & 100 & 1100 & 100 \\
\hline
\end{tabular}

shows average of approximately one third $(32.9 \%)$ of all the news pieces is opened in the headlines. It is notable that radio Afghanistan with $26.0 \%$ operates less with headlines that the other stations. Killed radio with $42.1 \%$ on the other hand remarkably exceeds the average.

There were four possible forms: news piece only (only a speaker/anchor who reads the news). Dispatch piece (anchor/speaker read and additional voice are heard like sources or correspondents), but it is not more than on and half minutes. Package (anchor/speaker and additional voices are including dispatch, sources voices, sound effects, vox-pop), the time duration it also is from $3 \mathrm{mi}$ nutes to five minutes, declare or explain the news with all details. And the last is commentary (a speaker reads a comment or other opinion piece, or gets an interview amongst the news item, with sources to get more information with details and for declare the event from one minute to five minutes), and more than five minutes, more than it depends on story. The results show that four forms news piece only, news piece with dispatch, news piece, with dispatch and additional voices of sources with sound effects and voice of correspondent and commentary are represented in the sample. This leads to the conclusion that Afghanistan's radio broadcasters do consider all these above forms in the news bulletins and especially in the news magazines. Table 4 shows that BBC Radio is the station which most frequently includes sound-bites of sources and additional voices (64.9\%) followed by Radio Azadi by (61.5\%).

Table 5 shows length of the stories was counted in characters (without spaces) of the transcripts. Short news reports were designed as of up to 800 characters' cone minute. Meddle length news subdivided in: medium one up to 1400 characters (one minute and 45 seconds); medium two 2000 characters (two minutes and 30 seconds). Long news equal up to 3500 characters (around 4 minutes); and Very long news is longer than 3500 characters (more than 4 minutes). All news could be assigned to a length category, although some news pieces could not be transcribed in full due to pro or sound quality. Almost half of all news pieces (45.5\% on average) belong to the category short news. Killid Radio (57.7\%) is the station with shortest news compared to Radio Azadi (45.0\%), Radio Afghanistan (42.1\%), and BBC Radio (40.3\%). For BBC Radio it is noticeable that the rest of the news are almost equally allotted to the further length categories (medium one: 15.6\%; medium two 15.6\%; long: 15.6; very long: 13.0\%). All four stations show remarkable differences on the level of long and very long 
Table 4. Form of news reports.

\begin{tabular}{cccccc}
\hline \multirow{2}{*}{ Form } & \multicolumn{5}{c}{ Medium } \\
\cline { 2 - 5 } & BBC Radio & Afghanistan & Killid Radio & Radio Azadi & \\
\hline News piece only & $35.1 \%$ & $47.3 \%$ & $39.1 \%$ & $38.5 \%$ & $40.0 \%$ \\
Dispatch & $37.2 \%$ & $30.1 \%$ & $34.7 \%$ & $34.9 \%$ & 34.22 \\
Package & $23.4 \%$ & $18.4 \%$ & $22.3 \%$ & $21.2 \%$ & $21.32 \%$ \\
Commentary & $4.3 \%$ & $4.2 \%$ & $3.9 \%$ & $5.4 \%$ & $4.45 \%$ \\
Total No. & 141 & 162 & 159 & 153 & 615 \\
$\%$ & 100 & 100 & 100 & 100 & 100 \\
\hline
\end{tabular}

Table 5. Length of news reports.

\begin{tabular}{cccccc}
\hline \multirow{2}{*}{ Length of news reports } & \multicolumn{5}{c}{ Medium } \\
\cline { 2 - 5 } & BBC Radio & Afghanistan & Killid Radio & Radio Azadi & \\
\hline Short & $40.3 \%$ & $42.1 \%$ & $57.7 \%$ & $45.0 \%$ & $45.5 \%$ \\
Medium one & $15.6 \%$ & $24.6 \%$ & $15.4 \%$ & $11.7 \%$ & $16.7 \%$ \\
Medium two & $15.6 \%$ & $12.3 \%$ & $13.5 \%$ & $11.7 \%$ & $13.4 \%$ \\
Long & $15.6 \%$ & $15.8 \%$ & $13.5 \%$ & $30.0 \%$ & $18.7 \%$ \\
Very long & $13.0 \%$ & $5.3 \%$ & $0.0 \%$ & $1.7 \%$ & $5.7 \%$ \\
Total No. & 141 & 162 & 159 & 153 & 615 \\
$\%$ & 100 & 100 & 100 & 100 & 100 \\
\hline
\end{tabular}

size news: Radio Azadi that has comparatively little medium sized news (11.7\% each on level medium one, and medium two) shows the strongest representation in the segment of long news $(30.0 \%)$. The other three stations-BBC Radio proves to be the only station with a notable amount of much sized news (13.0\%). Killid Radio does not have any news in this category and also Radio Azadi (1.7\%) and Radio Afghanistan (5.3\%) lie behind.

Table 6 shows that the national and local perspective generally dominates news reporting on Afghanistan's radio stations. Radio Afghanistan (74.7\%), Killid Radio (69.5\%) and Radio Azadi (57.6\%) in more than half of their cases geographically refer to Afghanistan only. Accordingly, low is the share of purely international news ( $11.8 \%$ on coverage or mixed news $24.0 \%)$. The fact that BBC Radio has a comparatively high international orientation might be explained with its role as a radio broadcaster who is expected to report on diplomatic activities and international occurrences.

On the local level according to the result is Table 7 Radio Afghanistan with its high share of regional news (36.0\%) remarkably differs from the other station. For BBC Radio, the contrary has to be stated as the station mere $(10.2 \%)$ of it cases deals with specific regional respective. This distinction seems to be clearly attributable to Afghanistan's radio stations, unique position in having regional correspondents that cover news stories from the countries. News reports which 
Table 6. Geographic reference.

\begin{tabular}{cccccc}
\hline \multirow{2}{*}{ Geographic Reference } & \multicolumn{5}{c}{ Medium } \\
\cline { 2 - 6 } & BBC Radio & Afghanistan & Killid Radio & Radio Azadi & \\
\hline Afghanistan news only & $48.3 \%$ & $74.7 \%$ & $69.5 \%$ & $57.6 \%$ & $62.5 \%$ \\
Afghanistan with foreign & $30.2 \%$ & $16.2 \%$ & $25.3 \%$ & $26.8 \%$ & $24.6 \%$ \\
Foreign countries only & $20.8 \%$ & $8.3 \%$ & $5.1 \%$ & $14.9 \%$ & $12.3 \%$ \\
No geographic reference & $0.7 \%$ & $0.8 \%$ & $0.1 \%$ & $0.7 \%$ & 0.6 \\
Total No. & 141 & 162 & 159 & 153 & 615 \\
$\%$ & 100 & 100 & 100 & 100 & 100 \\
\hline
\end{tabular}

Table 7. Regional reference.

\begin{tabular}{cccccc}
\hline \multirow{2}{*}{ Regional Reference } & \multicolumn{5}{c}{ Medium } \\
\cline { 2 - 6 } & BBC Radio & Afghanistan & Killid Radio & Radio Azadi & \\
\hline Only Kabul & $16.3 \%$ & $12.0 \%$ & $32.1 \%$ & $15.8 \%$ & $19.05 \%$ \\
Regional Zone & $10.2 \%$ & $36.0 \%$ & $21.4 \%$ & $17.5 \%$ & $21.26 \%$ \\
National whole country & $42.9 \%$ & $34.7 \%$ & $36.9 \%$ & $43.9 \%$ & $39.5 \%$ \\
Not related & $30.6 \%$ & $17.3 \%$ & $9.6 \%$ & $22.8 \%$ & $20.1 \%$ \\
Total No. & 75 & 113 & 109 & 95 & 392 \\
$\%$ & 100 & 100 & 100 & 100 & 100 \\
\hline
\end{tabular}

refer to the nation as a whole are rather frequent on all four stations, though more pronounced on Radio Azadi (43.9\%) and BBC Radio (42.9\%) than on Radio Afghanistan (34.7\%) and Killid Radio (33.9\%).

On the international level, Table 8 shows that BBC Radio shows on equivalent share of news referring to USA, and Europe (21.5\% each) on the one hand and Middle East (29.9\%) and Asia (30.1\%) on the other hand. Radio Azadi focuses on Europe (30.8\%) and deals with news concerning the USA (23.1\%) more often than with the Asia (23.1\%); and less focuses on Middle East (15.4\%); the station did not consider more in Middle East. Radio Afghanistan and Killid Radio afford a comparatively higher share of news concerning Asia, Europe and USA than the other two stations. Further regions are almost completely lacking.

One focal point of the preparation training had been to enable coders to define and count the sound-bites. As to how the coders coped with that challenge mixed results have to be stated: the researcher had emphasized that in an interview (questions of journalist answered by one source) all sound-bites of the interviewee have to be summarized to one sound-bite instead of counting every answer or statement separately. That instruction amongst others was hot strictly followed. Hence one can suppose a tendency towards too many sound-bites in the data. This has to be kept in mind when at the following results.

According to researcher, Table 9, and some of his friends who were as coders, findings more than half of all news pieces $(52.8 \%)$ do not include any sound-bites 
Table 8. International reference; percentage of news referring to international context; base of $\mathrm{N}=$ all news, excluding all news for which the international reference was not applicable.

\begin{tabular}{cccccc}
\hline \multirow{2}{*}{$\begin{array}{c}\text { International } \\
\text { Reference }\end{array}$} & BBC Radio & Afghanistan & Killid Radio & Azadi Radio & Total No. \\
\cline { 2 - 5 } Europe & $21.5 \%$ & $14.5 \%$ & $25.5 \%$ & $30.8 \%$ & $23.0 \%$ \\
Asia & $30.1 \%$ & $44.1 \%$ & $36.7 \%$ & $23.1 \%$ & $33.5 \%$ \\
USA & $21.5 \%$ & $20.4 \%$ & $17.7 \%$ & $23.1 \%$ & $20.6 \%$ \\
Middle East & $20.9 \%$ & $16.3 \%$ & $15.8 \%$ & $15.4 \%$ & $17.3 \%$ \\
Rest of the world & $6.0 \%$ & $4.7 \%$ & $4.3 \%$ & $7.6 \%$ & $5.6 \%$ \\
Total No. & 66 & 49 & 50 & 58 & 223 \\
\% & 100 & 100 & 100 & 100 & 100 \\
\hline
\end{tabular}

Table 9. Number of sound-bites.

\begin{tabular}{cccccc}
\hline \multirow{2}{*}{$\begin{array}{c}\text { Number of } \\
\text { Sound-bites }\end{array}$} & \multicolumn{5}{c}{ Medium } \\
\cline { 2 - 5 } & BBC Radio & Afghanistan & Killid Radio & Azadi Radio & \\
\hline 0 & $58.3 \%$ & $51.9 \%$ & $36.8 \%$ & $65.8 \%$ & $52.8 \%$ \\
1 & $23.3 \%$ & $10.4 \%$ & $31.6 \%$ & $19.9 \%$ & $19.9 \%$ \\
2 & $3.3 \%$ & $6.5 \%$ & $17.5 \%$ & $10.2 \%$ & $10.2 \%$ \\
3 & $6.7 \%$ & $7.8 \%$ & $5.3 \%$ & $5.2 \%$ & $5.7 \%$ \\
$4-5$ & $6.7 \%$ & $5.2 \%$ & $5.3 \%$ & $4.5 \%$ & $4.5 \%$ \\
6 and more & $1.7 \%$ & $18.2 \%$ & $3.5 \%$ & $6.9 \%$ & $6.9 \%$ \\
Total & 141 & 162 & 159 & 153 & 615 \\
$\%$ & 100 & 100 & 100 & 100 & 100 \\
\hline
\end{tabular}

at all. On the state run Radio Afghanistan this evens the case in almost half of all news pieces (51.9\%). Killid Radio by contrast just in (36.8\%) does not provide any rather big differences can also be stated for the use of one sound-bite. Killid Radio (31.6\%) is the leader in this category against BBC Radio with still (23.3\%) but Radio Azadi with only (19.9\%). For Radio Afghanistan one particular feature has to be considered: according to bare data the station performs low in the category 1 sound-bite (10.4\%) but has high ranking when it comes to 6 and more sound-bites (18.2\%). It is very probable that the two categories can be summed-up into one as the category 6 or more sound-bites presumably was assigned due to a misconception on the coders' side in the case of interviews. Consequently, Radio Afghanistan with (28.6\%) is the same level as leading Killid Radio. But Killid Radio held up the first position also on the levels between two and five sound-bites; with $(28.1 \%)$ it clearly beats the other stations (Radio Afghanistan: 19.5\%, Radio Azadi: 17.3\%, and BBC Radio: 16.7\%). Altogether the use three sound-bites or more is rather seldom $(10.2 \%$ on average, excluding the category six or more sound-bites for above mentioned reason). 
Especially for news reports with two sound-bites or more it is important to know whether one sound-bite provider is just repeated or whether there are various sound-bite providers, thus adding to diversity.

Table 10 shows that Killid Radio according to the coders findings provide most sound-bites but also offers the largest share of sound-bites providers. In (26.3\%) of its new pieces there are two and more different sound-bites providers followed by Radio Afghanistan (10.4\%), BBC Radio (10.0\%) and Radio Azadi (7.7\%). Comparing the numbers of sound-bites and sound-bite providers, Killid Radio also shows the highest congruency: when the station offers two or more sound-bites ( $28.1 \%$ of 2 - 5 sound-bites) they mostly can be traced back to two or more sound-bites providers $(26.3 \%)$. The other three stations often repeat sound-bites providers. Although according to the coders Radio Afghanistan offers in $(19.5 \% 2$ - 5) sound-bites those less frequently result from two or more sound-bite providers (10.4\%). The same tendency has to be stated for BBC Radio (16.7\% of two to five sound-bites/10.0\% of two or more sound-bite providers). Thus, Killid Radio allows more different actors speaking on the radio.

Table 11 shows the topic ranges according to the codebook turned out to be quite suitable as the overall share of other topic remained rather low (11.5\%). Nevertheless, it would be interesting to find out for BBC Radio, the station with the highest number of other $(4.8 \%)$, whether it would make sense to introduce additional single topics and thereby increase accuracy. The table shows the topic list after having been re-grouped:

According to Table 12 high politics, and economics were the most significant topic groups-both most distinctively Radio Azadi with a rate of $21.0 \%)$ of news pieces on high politics and of $(22.2 \%)$ on terrorism and security. The general high share of economics might surprise does one link it with the finding that economic actor groups ( $1.7 \%$ in average) or source groups $(0.7 \%$ on average) were almost inexistent in the sample. It might be explained by the fact that news on infrastructure, agriculture and development co-operation is not necessarily linked to economic actors or sources. Often governmental actors take the lead in those areas as reconstruction of public infrastructure is the key issues in Radio

Table 10. Number of sound-bite providers.

\begin{tabular}{|c|c|c|c|c|c|}
\hline \multirow{2}{*}{$\begin{array}{c}\text { Number of sound-bite } \\
\text { providers }\end{array}$} & \multicolumn{4}{|c|}{ Medium } & \multirow{2}{*}{ Total No. } \\
\hline & BBC Radio & Afghanistan & Killid Radio & Radio Azadi & \\
\hline 0 & $58.3 \%$ & $58.3 \%$ & $36.8 \%$ & $71.2 \%$ & $56.1 \%$ \\
\hline 1 & $31.7 \%$ & $31.2 \%$ & $36.8 \%$ & $21.2 \%$ & $30.5 \%$ \\
\hline 2 & $4.7 \%$ & $7.8 \%$ & $15.8 \%$ & $5.8 \%$ & $8.9 \%$ \\
\hline 3 & $3.3 \%$ & $1.3 \%$ & $3.5 \%$ & $1.9 \%$ & $2.4 \%$ \\
\hline 4 and more & $0.0 \%$ & $1.3 \%$ & $7.0 \%$ & $0.0 \%$ & $2.0 \%$ \\
\hline Total No. & 141 & 162 & 159 & 153 & 615 \\
\hline$\%$ & 100 & 100 & 100 & 100 & 100 \\
\hline
\end{tabular}


Table 11. Re-grouped topics; base of $\mathrm{N}=$ all news, purely international news excluded (392 news reports).

\begin{tabular}{|c|c|c|c|c|c|}
\hline \multirow{2}{*}{ Topic Group } & \multicolumn{4}{|c|}{ Medium } & \multirow{2}{*}{$\begin{array}{l}\text { Total } \\
\text { No. }\end{array}$} \\
\hline & BBC Radio & Afghanistan & Killid Radio & Azadi Radio & \\
\hline High politics & $18.6 \%$ & $17.4 \%$ & $19.0 \%$ & $21.0 \%$ & $19.0 \%$ \\
\hline Conflicts/Events & $16.9 \%$ & $14.5 \%$ & $15.6 \%$ & $16.3 \%$ & $15.8 \%$ \\
\hline Terrorism and Security & $27.3 \%$ & $15.9 \%$ & $20.1 \%$ & $22.2 \%$ & $21.3 \%$ \\
\hline Social and Culture & $2.9 \%$ & $11.6 \%$ & $7.3 \%$ & $3.4 \%$ & $6.3 \%$ \\
\hline Economics & $9.1 \%$ & $10.8 \%$ & $9.8 \%$ & $8.2 \%$ & $9.4 \%$ \\
\hline Reconstruction and development & $2.5 \%$ & $9.1 \%$ & $6.1 \%$ & $4.2 \%$ & $5.4 \%$ \\
\hline Narcotic & $9.5 \%$ & $8.3 \%$ & $10.9 \%$ & $11.1 \%$ & $9.9 \%$ \\
\hline Religion & $0.5 \%$ & $0.9 \%$ & $0.3 \%$ & $0.3 \%$ & $0.6 \%$ \\
\hline Media and Freedom of P/Ex & $4.9 \%$ & $3.8 \%$ & $4.9 \%$ & $4.1 \%$ & $4.4 \%$ \\
\hline Sports & $3.0 \%$ & $4.2 \%$ & $4.3 \%$ & $5.2 \%$ & $4.2 \%$ \\
\hline Others & $4.8 \%$ & $3.5 \%$ & $1.75 \%$ & $4.3 \%$ & $3.5 \%$ \\
\hline Total No. & 75 & 113 & 109 & 95 & 392 \\
\hline$\%$ & 100 & 100 & 100 & 100 & 100 \\
\hline
\end{tabular}

Table 12. Re-grouped actors; percentage of news with an actor from the actor groups; three most important actors in all news identified. Base of $\mathrm{N}=$ all news, purely international news and sports excluded, in total 392 different actors.

\begin{tabular}{|c|c|c|c|c|c|c|}
\hline \multirow[b]{2}{*}{ Actor Groups } & \multicolumn{4}{|c|}{ Medium } & \multirow[b]{2}{*}{$\varnothing$} & \multirow[b]{2}{*}{ Number } \\
\hline & BBC Radio & Afghanistan & $\begin{array}{l}\text { Killid } \\
\text { Radio }\end{array}$ & $\begin{array}{l}\text { Radio } \\
\text { Azadi }\end{array}$ & & \\
\hline Executive Govt. & $37.1 \%$ & $26.7 \%$ & $30.6 \%$ & $37.0 \%$ & $32.2 \%$ & 126 \\
\hline Political parties \& personal & $11.4 \%$ & $7.9 \%$ & $4.8 \%$ & $8.0 \%$ & $6.7 \%$ & 27 \\
\hline Legislative Govt. & $13.6 \%$ & $7.9 \%$ & $12.1 \%$ & $14.0 \%$ & $11.5 \%$ & 45 \\
\hline Independent Institutions & $3.8 \%$ & $3.0 \%$ & $2.4 \%$ & $2.0 \%$ & $2.9 \%$ & 11 \\
\hline Civil society (national) & $1.5 \%$ & $6.7 \%$ & $6.5 \%$ & $5.0 \%$ & $5.0 \%$ & 20 \\
\hline International Groups & $6.8 \%$ & $13.9 \%$ & $12.9 \%$ & $11.0 \%$ & $11.3 \%$ & 44 \\
\hline Economy & $3.0 \%$ & $1.8 \%$ & $0.0 \%$ & $2.0 \%$ & $1.7 \%$ & 7 \\
\hline Professional & $0.8 \%$ & $1.8 \%$ & $1.6 \%$ & $1.0 \%$ & $1.3 \%$ & 5 \\
\hline General public & $13.6 \%$ & $19.4 \%$ & $18.5 \%$ & $9.0 \%$ & $15.7 \%$ & 62 \\
\hline Media & $4.5 \%$ & $7.3 \%$ & $2.4 \%$ & $6.0 \%$ & $5.2 \%$ & 20 \\
\hline Others & $2.3 \%$ & $3.6 \%$ & $4.0 \%$ & $1.0 \%$ & $2.9 \%$ & 11 \\
\hline $\begin{array}{l}\text { Target groups development } \\
\text { cooperation }\end{array}$ & $1.5 \%$ & $4.2 \%$ & $4.0 \%$ & $4.0 \%$ & $3.5 \%$ & 14 \\
\hline Total No. & 75 & 113 & 109 & 95 & & 392 \\
\hline$\%$ & 100 & 100 & 100 & 100 & 100 & \\
\hline
\end{tabular}

Afghanistan economic news who even takes the first place among the topics the station deals with. The result might reflect that in the status-quo of the country 
news on economic recovery are very important and thus news worthy.

Sport was rather relevant for all four radio stations most, explicitly for radio Azadi (5.2\%). Questions concerning terrorism and security and terrorism in global issues were hardly an explicit subject during the last one and half decade, the assessed period in Afghanistan. BBC Radio, Radio Azadi, after that Killid Radio were the stations which touched it at all. For this aspect it could be important as well as valuable to analyze a sample of a more recent date: Did the terrorism and Taliban war remain disregarded in Afghanistan news even after the trial against Taliban and opposition of government was opened? Conflict and events-may they be personal or political, happening between governmental and other organizational or civil entities-play a bigger role according to Table 12 on BBC Radio (16.9\%) and Radio Azadi (16.3\%), than on Killid Radio (15.6\%) and Radio Afghanistan (14.5\%). Adding up the four most important topics for each station it can be stated that Radio Afghanistan offer the smallest topic range: the four leading topics occupy (85\%) got of the station's news magazine. Radio Azadi (66.6\%) and Killid Radio (63.6\%) got a more diverse set with their four leading topics occupying a smaller share.

The institutions of executive government comprising the president, the cabinet, the ministers, other central authorities and local administrations take the leading position on all. Four stations, most notable on BBC Radio (37.1\%) and Radio Azadi (37.0\%). Table 12 shows political parties play a much bigger role on BBC Radio (11.4\%) than on Radio Afghanistan (7.9\%) and Killid Radio (4.8\%). The parliament is quite equally represented on BBC Radio (12.1\%) and Radio Azadi (14.0\%). Radio Afghanistan is behind the others in this aspect (7.9\%). Civil society is mentioned more often by Radio Afghanistan, Killid Radio and Radio Azadi (around 5\% to 7\%) and BBC Radio (1.5\%).

Although economy played a key part as a topic, economic actors are hardly represented in the news, international groups (including aid organizations, like; international NGOs and inter-governmental bodies) play a much bigger role for all stations. People from the general public are quite important actors in radio news (15.7\% on average), with Radio Afghanistan leading (19.4\%) closely followed by Killid Radio (18.5\%). Radio Azadi lags behind (9.0\%) in this regard. It points towards a tendency of reporting for the people when the ordinary people are perceived as actors in the news.

Radio Afghanistan (4.2\%), Killid Radio (4.0\%) and Radio Azadi (4.0\% pay more attentions to the typical target groups of development co-operation (such us refugees, migrants, ex-combatants, youth, disabled, women, people with health) that BBC Radio (1.5\%).

Table 13 shows all news contains a description of the event or problem (what?). The immediate reason for an event or problem (why?) is usually given though less frequently on Radio Azadi (78.4\%) than on the other three stations Killid Radio (86.3\%), Radio Afghanistan (85.5\%) and BBC Radio (85.4\%). The average of background information (20.2\%) is lathering low. Yet Radio Afghanistan $(30.6 \%)$ notably outperforms the other stations. this finding can be taken 
Table 13. Analysis of reporting style (depth levels); percentage of news covering different levels of reporting; base of $\mathrm{N}=$ all news, purely international news and sport news excluded.

\begin{tabular}{ccccccc}
\hline \multirow{2}{*}{ Depth Levels } & \multicolumn{2}{c}{ Medium } & \multicolumn{1}{c}{ Number } \\
\cline { 2 - 5 } & BBC Radio & Afghanistan & Killid Radio & Radio Azadi & & \\
\hline What? & $100 \%$ & $100 \%$ & $100 \%$ & $100 \%$ & $100 \%$ & 392 \\
Why? & $85.4 \%$ & $85.5 \%$ & $86.3 \%$ & $78.4 \%$ & $84.3 \%$ & 330 \\
Background & $16.7 \%$ & $30.6 \%$ & $15.7 \%$ & $20.5 \%$ & $20.2 \%$ & 79 \\
Consequences & $29.2 \%$ & $21.6 \%$ & $25.5 \%$ & $40.3 \%$ & $30.3 \%$ & 118 \\
\hline
\end{tabular}

as encouraging as it shows that under given circumstances Afghanistan's radio stations-beyond mere reporting-can contribute to the orientation of citizens. Owning to quality of data (see next paragraph) the result for Radio Afghanistan should not be overrated though.

Reporting on the potential consequences of news (30.3\%) is generally provided to a lower extent reporting on the background. Also in this aspect Radio Afghanistan (21.6\%) and Radio Azadi with (40.3\%) a larger extent reporting on the background considerably outperforms the other stations. In addition, it was examined how often three different depth levels-beside "what" which was appointed in $100 \%$ of all cases-wore integrated into one news report. According to the research coders that show in Table 14, findings BBC Radio is the station where most frequently two or more depth levels wore considered (43.4\%), Killid Radio is on the second place (34.6\%) though it never considered more than two depth levels. These results have to be taken with caution though as the analysis of data quality shows (see next paragraph).

As introductorily mentioned the researcher re-coded a part of the news magazines, comparing own data with the coders results it has to be stated that the coders were not always able to identify in the news piece. Therefore, one can suppose that the share of news magazine answering to why? Tend to be bigger than stated in this paragraph. On the other hand, the proportion of news pieces outlining the background might lie below the coders' results. The reason: the coder party misconceived extensive reporting on pure facts as background. But such detailed reporting does not fulfill the criteria of real background information as it does not refer to a larger (e.g. lime) horizon nor to deeper-lying reasons.

Table 15 shows concerning the perspective of public discourse Azadi Radio (22.6\%) tops the other stations by far. Radio Afghanistan ranks behind (15.3\%). This leads to the conclusion that the state run broadcaster does not promote public discourse, a statement which is backed by the analysis of sources. Killid Radio providers a rather low ragger of sources; the four most important sources mount to $73.6 \%$ (see who are the sources?). This might offer one explanation why the share of public discourse is comparatively low. Similarly, small is the percentage of public discourse on Radio Afghanistan (15.3\%), the station with a 
Table 14. Number of depth levels; percentage of news covering different levels of reporting; base of $\mathrm{N}=$ all news, purely international news, and sport news excluded.

\begin{tabular}{ccccccc}
\hline \multirow{2}{*}{$\begin{array}{c}\text { Number of } \\
\text { depth levels }\end{array}$} & \multicolumn{9}{c}{ Medium } & \multicolumn{1}{c}{ Total No. } \\
\cline { 2 - 5 } & BBC Radio & Afghanistan & Killid Radio & Radio Azadi & & \\
\hline 1 & $13.5 \%$ & $18.8 \%$ & $10.9 \%$ & $20.0 \%$ & $15.7 \%$ & 61 \\
2 & $51.9 \%$ & $37.7 \%$ & $61.8 \%$ & $60.0 \%$ & $51.4 \%$ & 60 \\
3 & $34.6 \%$ & $27.5 \%$ & $25.5 \%$ & $15.0 \%$ & $26.4 \%$ & 104 \\
4 & $0.0 \%$ & $15.9 \%$ & $1.8 \%$ & $5.0 \%$ & $6.5 \%$ & 25 \\
Total No. & 75 & 113 & 109 & 95 & & 392 \\
$\%$ & 100 & 100 & 100 & 100 & 100 & \\
\hline
\end{tabular}

Table 15. Perspectives in radio news; percentage of news covering different pre-defined perspectives; base of $\mathrm{N}=$ all news, excluding purely international news as well as sports news.

\begin{tabular}{|c|c|c|c|c|c|c|}
\hline \multirow[b]{2}{*}{ Perspectives } & \multicolumn{4}{|c|}{ Medium } & \multirow[b]{2}{*}{$\varnothing$} & \multirow[b]{2}{*}{ Number } \\
\hline & $\begin{array}{l}\text { BBC } \\
\text { Radio }\end{array}$ & Afghanistan & $\begin{array}{l}\text { Killid } \\
\text { Radio }\end{array}$ & $\begin{array}{l}\text { Radio } \\
\text { Azadi }\end{array}$ & & \\
\hline Public discourse/political struggle & $25.4 \%$ & $15.3 \%$ & $22.8 \%$ & $26.6 \%$ & $22.4 \%$ & 88 \\
\hline Concerns of ordinary people & $34.9 \%$ & $22.2 \%$ & $27.5 \%$ & $53.9 \%$ & $34.6 \%$ & 135 \\
\hline
\end{tabular}

pronounced amount of government sources. Radio Azadi strikes with its big share of news pieces including ordinary people's perspective (53.9\%). Also BBC Radio shows a high share in this regard (34.9\%) according to the coders, findings, Radio Afghanistan on the other hand a comparatively low one (22.2\%).

Table 16 shows Average number of sources BBC Radio (1.51\%) tops the other stations by far. Radio Afghanistan ranks the lowest number sources usage (1.21.3\%). This leads the attention of media in news sources.

Joust $5.6 \%$ of news had no mentioned sources at all. Table 17 shows Radio Azadi is outstanding in this regard; in just $2.0 \%$ of its news no sources are mentioned. However, rather frequently there was only one source (62.6\%). This has to be seen in conjunction with the hard working conditions Afghanistan journalists face, such as very restricted time and financial resources. BBC Radio has the highest average of sources numbers (1.51 sources per news), Radio Afghanistan the lowest (1.21 per news). Radio Azadi (1.38 sources per news), and Killid Radio (1.35 per news) are in between. Consistently with its top position regarding number of sound-bite providers Killid Radio proves to be the station with the biggest share of two or more sources (67.2\%) followed by BBC Radio (42.7\%) and Radio Afghanistan (42.6\%). Radio Azadi is the last in this regard (22.9\%).

Table 18 shows BBC Radio relies in $37.1 \%$ of all its news and thus to a much higher extent than the other stations on sources related to the executive government. However, it needs to be considered that Radio Afghanistan has the highest 
Table 16. Average number of sources; percentage of different number of sources; base of $\mathrm{N}=$ all news, excluding purely international news and sport. Cases with more than six sources ( 3 cases, plus 3 cases with 88 ) were excluded as one can suppose that they happened due to a misconception of the coders.

\begin{tabular}{cccccc}
\hline \multirow{2}{*}{$\begin{array}{c}\text { Average number } \\
\text { of sources }\end{array}$} & \multicolumn{5}{c}{ Medium } \\
\cline { 2 - 5 } & BBC Radio & Afghanistan & Killid Radio & Radio Azadi & \\
\hline$\varnothing$ & $1.51 \%$ & $1.21 \%$ & $1.35 \%$ & $1.38 \%$ & 1.37 \\
No. & 128 & 103 & 114 & 118 & 463 \\
\hline
\end{tabular}

Table 17. Diversity of sources; percentage of different number of sources; base of $\mathrm{N}=$ all news, excluding purely international news and sport. Cases with more than six sources (3 cases, plus 3 cases with 88) were excluded.

\begin{tabular}{ccccccc}
\hline \multirow{2}{*}{ Source number } & \multicolumn{7}{c}{ Medium } & \multirow{2}{*}{$\varnothing$} & Total No. \\
\cline { 2 - 5 } & BBC Radio & Afghanistan & Killid Radio & Radio Azadi & & \\
\hline 0 & $6.5 \%$ & $8.1 \%$ & $6.3 \%$ & $2.0 \%$ & $5.6 \%$ & 26 \\
1 & $61.3 \%$ & $56.8 \%$ & $70.8 \%$ & $60.8 \%$ & $62.6 \%$ & 289 \\
2 & $24.2 \%$ & $24.3 \%$ & $14.0 \%$ & $27.5 \%$ & $22.7 \%$ & 105 \\
3 & $6.5 \%$ & $10.8 \%$ & $6.3 \%$ & $7.8 \%$ & $7.6 \%$ & 36 \\
4 and more & $1.6 \%$ & $0.0 \%$ & $2.1 \%$ & $2.0 \%$ & $1.5 \%$ & 7 \\
Total No. & 128 & 103 & 114 & 118 & & 463 \\
$\%$ & 100 & 100 & 100 & 100 & 100 & \\
\hline
\end{tabular}

Table 18. Re-grouped sources; percentage of news with a source from the source groups; three most important sources in all news identified. Base of $\mathrm{N}=$ all news, purely international news and sport news excluded, in total 392 different news.

\begin{tabular}{|c|c|c|c|c|c|c|}
\hline \multirow[b]{2}{*}{ Source Groups } & \multicolumn{4}{|c|}{ Medium } & \multirow[b]{2}{*}{$\varnothing$} & \multirow[b]{2}{*}{ Number } \\
\hline & $\begin{array}{c}\text { BBC } \\
\text { Radio }\end{array}$ & Afghanistan & $\begin{array}{l}\text { Killid } \\
\text { Radio }\end{array}$ & $\begin{array}{l}\text { Radio } \\
\text { Azadi }\end{array}$ & & \\
\hline Executive Govt. & $37.1 \%$ & $26.7 \%$ & $30.6 \%$ & $37.0 \%$ & $32.2 \%$ & 126 \\
\hline Political parties \& personal & $11.4 \%$ & $7.9 \%$ & $4.8 \%$ & $8.0 \%$ & $6.7 \%$ & 27 \\
\hline Legislative Govt. & $13.6 \%$ & $7.9 \%$ & $12.1 \%$ & $14.0 \%$ & $11.5 \%$ & 45 \\
\hline Independent Institutions & $3.8 \%$ & $3.0 \%$ & $2.4 \%$ & $2.0 \%$ & $2.9 \%$ & 11 \\
\hline Civil society (national) & $1.5 \%$ & $6.7 \%$ & $6.5 \%$ & $5.0 \%$ & $5.0 \%$ & 20 \\
\hline International Groups & $6.8 \%$ & $13.9 \%$ & $12.9 \%$ & $11.0 \%$ & $11.3 \%$ & 44 \\
\hline Economy & $3.0 \%$ & $1.8 \%$ & $0.0 \%$ & $2.0 \%$ & $1.7 \%$ & 7 \\
\hline Professional & $0.8 \%$ & $1.8 \%$ & $1.6 \%$ & $1.0 \%$ & $1.3 \%$ & 5 \\
\hline General public & $13.6 \%$ & $19.4 \%$ & $18.5 \%$ & $9.0 \%$ & $15.7 \%$ & 62 \\
\hline Media & $4.5 \%$ & $7.3 \%$ & $2.4 \%$ & $6.0 \%$ & $5.2 \%$ & 20 \\
\hline Others & $2.3 \%$ & $3.6 \%$ & $4.0 \%$ & $1.0 \%$ & $2.9 \%$ & 11 \\
\hline Target groups development cooperation & $1.5 \%$ & $4.2 \%$ & $4.0 \%$ & $4.0 \%$ & $3.5 \%$ & 14 \\
\hline Total No. & 75 & 113 & 109 & 95 & & 392 \\
\hline$\%$ & 100 & 100 & 100 & 100 & 100 & \\
\hline
\end{tabular}


non-transparent sources, so it might have more government sources than it mentions (see Table 19). Killid Radio has the widest range of different source groups. The four most frequently quoted, sources groups mount up to $(69.4 \%)$ on Killid Radio in comparison to BBC Radio (62.9\%), Radio Azadi (63.0\%) and Radio Afghanistan (74.3\%) (Calculation based on Table 18). Civil society rather gets a word on Radio Afghanistan (6.7\%) and Killi Radio (6.5\%) than on the other two stations.

Taccording to the result which shows in Table 19, the same as for civil society can be said for the general public as a source (represented with 19.4\% Radio Afghanistan and $18.5 \%$ Killid Radio). It is very interesting that two broadcasters do not only use the general public as an actor in the news, but also as a source. Thus, the voice of ordinary people is really present, in comparison to BBC Radio (13.6\%) and Radio Azadi (9.0\%) where they only play a minor role as sources. Radio Azadi outnumbers the others in the share of the parliament (14.0\%). Political parties have a rather low share on all four stations $(6.7 \%)$ on average. So do professionals (1.3\%). Voices from the economic division are almost inexistent (1.7\%) among the quoted sources.

Table 19 shows BBC Radio (91.7\%), Radio Azadi (88.1\%) and Killid Radio $(84.7 \%)$ declare the origin of their sources to a quite similar extent. Radio Afghanistan stands out for a low transparency of its sources; their origin is indicated in only $(64.2 \%)$ of the stations cases.

Table 20 shows BBC Radio the journalists own research (=own inquiry) serves as an initial point of news reports in still 52.7\%. Different events and occasions arranged by media-external actors and organizations played distinct roles of the four stations: Radio Afghanistan e.g. relied equally on press conferences (8.5\%), press releases $(7.0 \%)$ and other conferences/seminars $(7.0 \%) /$ meanwhile Killid Radio did more attention to press release at all. On Radio Azadi on the other hand press releases were the less $(10.6 \%)$ at all of after inquiries to create a news report. Other events such as official meetings and ceremonies were important for BBC Radio (18.0\%). One caveat is worth mentioning: the source contexts might be different due to differences in the real context, but could also be due to different habits of the Radio in telling the public about the source context.

Table 21 shows the executive government is the leading sound-bite providers

Table 19. Source transparency; percentage of news covering different levels of reporting; base of $\mathrm{N}=$ all news, purely international and sport news excluded.

\begin{tabular}{ccccccc}
\hline \multirow{2}{*}{ Source transparency } & \multicolumn{9}{c}{ Medium } & \multirow{2}{*}{ Total No. } \\
\cline { 2 - 5 } & BBC Radio & Afghanistan & Killi Radio & Radio Azadi & & \\
\hline Source identified & $91.7 \%$ & $82.3 \%$ & $84.7 \%$ & $88.1 \%$ & $82.3 \%$ & 322 \\
Source not identified & $8.3 \%$ & $11.7 \%$ & $15.3 \%$ & $10.7 \%$ & $11.7 \%$ & 46 \\
No Source & $0.0 \%$ & $4.6 \%$ & $0.0 \%$ & $1.2 \%$ & $1.45 \%$ & 6 \\
Number & 75 & 113 & 109 & 95 & & 932 \\
$\%$ & 100 & 98.6 & 100 & 100 & 95.45 & \\
\hline
\end{tabular}


Table 20. Source context; percentage of source context; base of $\mathrm{N}=$ all news, purely international news and sport news excluded; cases with the answer source context, unknown excluded.

\begin{tabular}{ccccccc}
\hline & \multicolumn{7}{c}{ Medium } & \multirow{2}{*}{ Total No. } \\
\cline { 2 - 5 } Source context & $\begin{array}{c}\text { BBC } \\
\text { Radio }\end{array}$ & Afghanistan & $\begin{array}{c}\text { Killid } \\
\text { Radio }\end{array}$ & $\begin{array}{c}\text { Radio } \\
\text { Azadi }\end{array}$ & $\varnothing$ & \\
\hline Press conference \& media event & $12.7 \%$ & $8.5 \%$ & $15.6 \%$ & $6.3 \%$ & $10.7 \%$ & 43 \\
Press release & $7.3 \%$ & $7.0 \%$ & $3.0 \%$ & $10.4 \%$ & $6.2 \%$ & 25 \\
Conference & $3.6 \%$ & $7.0 \%$ & $4.6 \%$ & $8.3 \%$ & $5.8 \%$ & 23 \\
Demonstration & $0.0 \%$ & $0.0 \%$ & $0.0 \%$ & $6.3 \%$ & $1.5 \%$ & 7 \\
Other event & $18.2 \%$ & $11.0 \%$ & $7.8 \%$ & $6.3 \%$ & $11.5 \%$ & 46 \\
Own inquiry by journalist & $52.7 \%$ & $20.0 \%$ & $51.8 \%$ & $52.1 \%$ & $44.0 \%$ & 173 \\
Written document & $1.8 \%$ & $0.0 \%$ & $2.0 \%$ & $2.1 \%$ & $1.4 \%$ & 6 \\
Quoted from news agency & $0.0 \%$ & $42.0 \%$ & $2.9 \%$ & $2.1 \%$ & $11.8 \%$ & 48 \\
Quoted from other media & $1.8 \%$ & $0.0 \%$ & $4.6 \%$ & $0.0 \%$ & $1.6 \%$ & 6 \\
Other & $1.8 \%$ & $0.0 \%$ & $4.6 \%$ & $4.2 \%$ & $2.6 \%$ & 11 \\
Call-in show & $0.0 \%$ & $4.2 \%$ & $4.0 \%$ & $2.1 \%$ & $2.5 \%$ & 10 \\
Total No. & 75 & 113 & 109 & 95 & & 392 \\
\% & 100 & 100 & 100 & 100 & 100 & \\
\hline
\end{tabular}

Table 21. Re-grouped sound-bites; percentage of re-grouped sound-bites; base of $\mathrm{N}=$ all news, purely international news and sport news excluded. Media as a sound-bite excluded.

\begin{tabular}{ccccccc}
\hline \multirow{2}{*}{ Re-grouped sound-bite } & \multicolumn{7}{c}{ Medium } & \multirow{2}{*}{ Total No. } \\
\cline { 2 - 5 } & $\begin{array}{c}\text { BBC } \\
\text { Radio }\end{array}$ & Afghanistan & $\begin{array}{r}\text { Killid } \\
\text { Radio }\end{array}$ & $\begin{array}{c}\text { Radio } \\
\text { Azadi }\end{array}$ & $\varnothing$ & \\
\hline Executive govt. & $49.1 \%$ & $30.0 \%$ & $30.8 \%$ & $24.2 \%$ & $33.5 \%$ & 130 \\
Political parties & $15.6 \%$ & $0.9 \%$ & $3.8 \%$ & $3.0 \%$ & $5.8 \%$ & 23 \\
Legislative govt. & $3.1 \%$ & $21.1 \%$ & $7.7 \%$ & $12.1 \%$ & $12.5 \%$ & 49 \\
Independent institutions & $10.5 \%$ & $0.0 \%$ & $3.8 \%$ & $3.0 \%$ & $4.3 \%$ & 17 \\
Civil society (national) & $3.1 \%$ & $5.0 \%$ & $7.7 \%$ & $9.1 \%$ & $6.9 \%$ & 27 \\
International groups & $2.0 \%$ & $15.0 \%$ & $7.7 \%$ & $6.1 \%$ & $7.9 \%$ & 31 \\
Economy & $3.1 \%$ & $0.0 \%$ & $0.0 \%$ & $6.1 \%$ & $2.3 \%$ & 8 \\
Professionals & $4.0 \%$ & $0.0 \%$ & $3.8 \%$ & $3.0 \%$ & $2.7 \%$ & 10 \\
General public & $3.1 \%$ & $0.0 \%$ & $23.1 \%$ & $24.1 \%$ & 13.6 & 54 \\
Others & $6.3 \%$ & $15.0 \%$ & $9.6 \%$ & $6.1 \%$ & $9.25 \%$ & 35 \\
Target groups development co-op. & $0.0 \%$ & $5.0 \%$ & $1.9 \%$ & $3.0 \%$ & $2.2 \%$ & 8 \\
Total No. & 75 & 113 & 109 & 95 & & 392 \\
\% & 100 & 100 & 100 & 100 & 100 & \\
\hline
\end{tabular}

on all four stations, most remarkable on BBC Radio with almost (49.1\%) government related sources. Radio Afghanistan considers the executive government 
with $(30.0 \%)$ and parliament speak out in (21.1\%) sources. Representative of the civil society get more often a possibility to speak out on Radio Azadi (9.1\%) and Killi Radio (7.7\%) than on the other two stations. International groups appear as sound-bites most frequently on Radio Afghanistan (15.0\%). As I mentioned above (see: geographic reference) this is probably due to the stations role as a state broadcaster reporting in diplomatic activities and international occurrences. Consistently with further findings Killid Radio (23.1\%) and Radio Azadi (24.2\%) do give the ordinary people a voice by conceding them airtime, i.e. direct speech. Radio Afghanistan by contrast does not provide any sound-bites of the general public at all. Political parties get more often a word on BBC Radio $(15.6 \%)$ than on the other stations. this result is consistent with finding in the categories source groups and actor group; in both categories political parties are stronger represented on BBC Radio than on the other stations.

Table 22 shows that it is quite common that sound-bite providers deliver information beyond what the speaker said preliminarily ( $87.0 \%$ on average). Radio Afghanistan is the station with the smallest number of sound-bites in which content additional to the speakers' introduction could be distinguished (59.4\%).

\section{Conclusion}

This study has highlighted the quality assessment of radio news programs in Afghanistan which are openers/headlines of the news, form of news reports, length of news reports, geographic references, number of sound-bites, numbers of sound-bite providers, topics, actors, and reporting style, respective of the news magazine, sources, sources transparency, sources context, sound-bites, and new information at news magazine. In the contemporary Afghanistan's radio stations, this was achieved by using the everyday magazine of four Afghanistan's radio channels, namely the Radio Afghanistan, Radio Azadi, Killid Radio and BBC Radio.

The presentation of data gives the researcher and reader of this research, a sense that news magazine in Afghanistan is one of the most popular as well as the most important programs of radio stations. Critically, radio news reporting is severely lack of professionalism. It is clear that there in BBC Radio and Radio Azadi is excellent news reporting being done; nevertheless, Radio Afghanistan has more opportunities and facilities to prepare good news program, but did not pay attentions to the style of writing and presentation of news. Although this study did not research other radio programs disciplines and format and the type

Table 22. New information in the sound-bites; percentage of sound-bites often additional information; base of $\mathrm{N}=$ all news, purely international and sport news excluded.

\begin{tabular}{ccccccc}
\hline \multirow{2}{*}{ Source content } & \multicolumn{9}{c}{ Medium } & \multirow{2}{*}{ Total No. } \\
\cline { 2 - 5 } & BBC Radio & Afghanistan & Killid Radio & Radio Azadi & & \\
\hline Yes & $97.1 \%$ & $59.4 \%$ & $89.1 \%$ & $97.5 \%$ & $87 \%$ & 341 \\
Total No. & 75 & 113 & 109 & 95 & & 392 \\
\hline
\end{tabular}


of preparation and coverage, they receive in the radio, it follows that there is an imitation model being employed by radio stations from BBC Radio. BBC Radio follows all principles and standards of journalism and news reporting in radio, but the writing style of BBC Radio vocabulary is not simple and limited, so it is sometimes difficult for listeners to understand the news events or news programs. On the contrary, Radio Azadi's writing style and reporting as well as presentation of news program is very simple, and listeners immediately can get the concept of news items. Both, Radio Azadi and BBC Radio have good financial opportunity as well as technical materials and salaries for their employees and journalists than Killid radio and Radio Afghanistan. Killid Radio as a local as well as private radio station, can't compete with BBC Radio or Radio Azadi; however it follows the standards of journalism and radio news reporting, with its less opportunities, like; technical materials and financial situation.

Foreign media are better than governmental as well as private and independent media in the country. Radio Afghanistan as the first radio station and state-run channel, is access all over the country and with more than one thousand employees could not broadcast good radio news program yet. Although radio news reporting seems to be in a crisis, the conflict (politics, elections, and etc) and terrorism and security sections seem to be thriving. This is obvious as a result, of the terrorism and security issues as well as democracy, which is not popular in Afghanistan. A case in point is that, Europe events, Asia and Middle East news, where covered almost daily in the news programs. These events are exactly what the NATO, and USA troops and government of Afghanistan want to see being covered by media, as the images activities and behavior of these phenomenon plays to the aspirations of many listeners that the radio stations want to attract.

Above all, media employees and journalism professions are not professionally completed. In addition, the freedoms of the expression and of the press have been guaranteed by the Afghanistan constitution. Since 2004, there is no any professional institution with all media nobilities to learn journalism employees and students as well as technically it is time consuming, we need to work hard in this area.

\section{Conflicts of Interest}

The authors declare no conflicts of interest regarding the publication of this paper.

\section{References}

ACSOR-Surveys (2010). Afghanistan Media Survey Report. https://acsor-surveys.com/wp-content/uploads/2010/09/afghanistan_media_survey.pdf

Altai Consulting \& Internews (2014). Afghan Media in 2014: Understanding the Audience.

http://www.altaiconsulting.com/wp-content/uploads/2016/05/Altai-Internews-Afghan$\underline{\text { Media-in-2014.pdf }}$ 
Altai Consulting \& Internews (2017). Local Radio in Afghanistan. https://internews.org/sites/default/files/Internews_Local_Radio_Afghanistan_2017-04. pdf

Bajraktari, Y., \& Parajon, C. (2008). Special Report on Media and Conflict: Afghanistan as a Relative Success Story. https://www.files.ethz.ch/isn/46714/sr198.pdf

BBC Media Action (2012). Policy Briefing on the Media of Afghanistan: The Challenges of Transition.

https://assets.publishing.service.gov.uk/media/57a08a8de5274a31e0000672/bbc_media _action_afghanistan_is_in_transition.pdf

Broadcasting Board of Governors (BBG) \& GALLUP (2015). Media Use in Afghanistan.

Chantler, P., \& Stewart, P. (2009). Essentials of Radio Journalism. London: Methuen Drama.

Chantler, P., \& Stewart, P. (2013). Basic Radio Journalism. London: Routledge Publication. https://doi.org/10.4324/9780080494029

Chapman, J., \& Kinsey, M. (2009). Broadcast Journalism: A Critical Introduction. London: Routledge Publication. https://doi.org/10.4324/9780203886458

Engstrom, G. (2020). Ten Years in Afghanistan. https://www.mediasupport.org/ten-years-in-afghanistan

Filak, V. F. (2018). Dynamics of News Reporting and Writing: Foundational Skills for a Digital Age. Oshkosh, WI: University of Wisconsin-Oshkosh, SAGE Publication.

Fraenkel, E., Schoemaker, E., \& Himelfarb, S. (2014). Afghanistan Media Assessment: Opportunities and Challenges for Peacebuilding.

https://www.usip.org/sites/default/files/resources/PW68_Afghanistan_Media_Assessm ent1.pdf

Gordon, A. (2005). Media and Global Change: Rethinking Communication for Development, Chapter 22, Radio in Afghanistan: Socially Useful Communications in Wartime. http://bibliotecavirtual.clacso.org.ar/clacso/coediciones/20100824075603/29Chapter22. pdf

Jawad, A. Q. (2013). Media Focus in Afghanistan News Coverage. https://scholarworks.uark.edu/cgi/viewcontent.cgi? article=1664\&context=etd

Prasad, B. D. (2019). Qualitative Content Analysis: Why Is It Still a Path Less Taken? https://www.qualitative-research.net/index.php/fqs/article/view/3392/4501 